\title{
Rescue ERCP after delayed migration of a lumen-apposing metal stent following endoscopic ultrasound-guided choledochoduodenostomy
}

Endoscopic retrograde cholangiopancreatography (ERCP) can be challenging in patients with altered anatomy or luminal narrowing. Endoscopic ultrasoundguided biliary drainage (EUS-BD) by placement of a lumen-apposing metal stent (LAMS; Hot-Axios; Boston Scientific, Marlborough, Massachusetts, USA) has emerged as an effective technique to allow biliary access after failed ERCP in a high-volume center [1].

A 46-year-old woman was referred to our hospital for acute cholangitis during chemotherapy for pancreatic cancer. She had undergone previous (5 weeks) EUS-BD with LAMS after two failed ERCPs in a peripheral hospital. Computed tomography showed migration of the LAMS distal flange within the duodenal wall, without evidence of perforation. Duodenoscopy confirmed correct position of the proximal flange within the duodenal bulb, and contrast swallow showed no extravasation of contrast medium or communication with the biliary tree. Normal papilla was identified in the second duodenum. A new ERCP achieved easy common bile duct (CBD) cannulation. Cholangiogram showed a dilated $\mathrm{CBD}$, no evidence of bile leakage, and a neoplastic distal stricture. At fluoroscopy, the LAMS distal flange was clearly outside the biliary tree ( $\downarrow$ Video $\mathbf{1}$ ). A fully covered metal stent was delivered across the neoplastic stricture and LAMS removal was performed. Contrast flushing across the duodenum did not show any leak; thus, the entry port was left open. The patient improved and was discharged 2 days later. This is the first case of rescue ERCP for LAMS migration after EUS-guided cho-

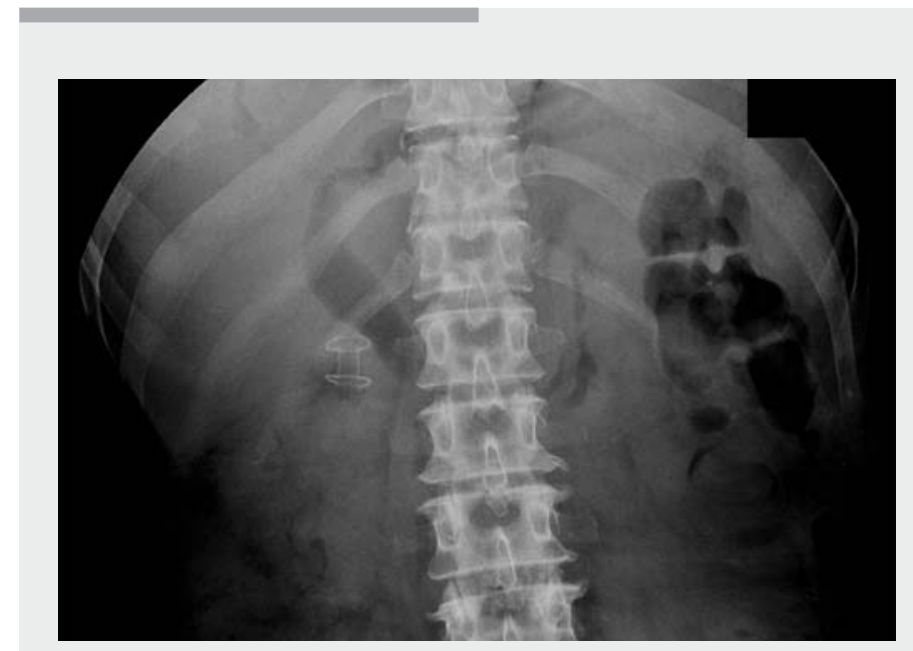

Video 1 The distal flange of the lumen-apposing metal stent was outside the biliary tree.

ledochoduodenostomy. Limited data on long-term follow-up after LAMS deployment are available [2] and no randomized trial has been conducted. Caution should be used when deciding on EUSBD after failed ERCP [3]. The best option is probably to refer the patient to a highvolume hospital, as LAMS may induce serious complications. Expertise in interventional endoscopy and therapeutic EUS is important because one could be the rescue therapy of the other.

Endoscopy_UCTN_Code_CPL_1AL_2AC FB

\section{Competing interests}

The authors declare that they have no conflict of interest.
The authors

Claudio Zulli ${ }^{1,2}$, Jean-Loup Dumont ${ }^{1}$, Fabrizio Cereatti ${ }^{3}$, Vincenzo Ceci ${ }^{4}$, Thierry Tuszynski ${ }^{1}$, Maurizio Fazi ${ }^{5}$, Gianfranco Donatelli ${ }^{1}$

1 Unité d'Endoscopie Interventionnelle, Hôpital Privé des Peupliers, Ramsay Santé, Paris, France

2 Digestive Endoscopy Unit, University Hospital G. Fucito, Ruggi d’Aragona, Salerno, Italy

3 Gastroenterology and Digestive Endoscopy Unit, ASST Ospedale Cremona, Cremona, Italy

4 Emergency Department, Ospedale Santo Spirito, Roma, Italy

5 Digestive Endoscopy Unit, Ospedale M.G. Vannini Figlie di San Camillo, Roma, Italy 


\section{Corresponding author}

\section{Gianfranco Donatelli, MD}

Unité d'Endoscopie Interventionnelle,

Ramsay Santé, Hôpital Privé des Peupliers,

8 Place de l'Abbé G. Hénocque, 75013 Paris,

France

Fax: +33-1-44165615

donatelligianfranco@gmail.com

\section{References}

[1] Attili F, Rimbas M, Galasso D et al. Fluoroless endoscopic ultrasound-guided biliary drainage after failed ERCP with a novel lumenapposing metal stent mounted on a cauterytipped delivery system. Endoscopy 2015; 47 (Suppl. 01): E619-E620
[2] Park DH, Jang JW, Lee SS et al. EUS-guided biliary drainage with transluminal stenting after failed ERCP: predictors of adverse events and long-term results. Gastrointest Endosc 2011; 74: 1276-1284

[3] Jain D, Shah M, Patel U et al. Endoscopic ultrasound guided choledocho-enterostomy by using lumen apposing metal stent in patients with failed endoscopic retrograde cholangiopancreatography: a literature review. Digestion 2018; 98: 1-10

\section{Bibliography}

DOI https://doi.org/10.1055/a-1073-7317

Published online: 20.12.2019

Endoscopy 2020; 52: E215-E216

(c) Georg Thieme Verlag KG

Stuttgart · New York

ISSN 0013-726X
ENDOSCOPY E-VIDEOS

https://eref.thieme.de/e-videos

口局 Endoscopy E-Videos is a free access online section, reporting 田: on interesting cases and new techniques in gastroenterological endoscopy. All papers include a high quality video and all contributions are freely accessible online.

This section has its own submission website at https://mc.manuscriptcentral.com/e-videos 